\title{
GMR
}

\section{Borax-induced apoptosis in HepG2 cells involves p53, Bcl-2, and Bax}

\author{
Y. Wei ${ }^{1}$, F.J. Yuan ${ }^{2}$, W.B. Zhou ${ }^{2}$, L. Wu ${ }^{2}$, L. Chen ${ }^{1}$, J.J. Wang ${ }^{1}$ and \\ Y.S. Zhang ${ }^{2}$ \\ ${ }^{1}$ Experiment Center of Medicine, DongFeng Hospital, \\ Hubei University of Medicine, Shiyan, Hubei, China \\ ${ }^{2}$ Institute of Liver Surgery, DongFeng Hospital, Hubei University of Medicine, \\ Shiyan, Hubei, China \\ Corresponding: Y.S. Zhang \\ E-mail: 57729968@qq.com
}

Genet. Mol. Res. 15 (2): gmr. 15028300

Received December 17, 2015

Accepted February 11, 2016

Published June 21, 2016

DOI http://dx.doi.org/10.4238/gmr. 15028300

\begin{abstract}
Borax, a boron compound and a salt of boric acid, is known to inhibit the growth of tumor cells. HepG2 cells have been shown to be clearly susceptible to the anti-proliferative effects of borax. However, the specific mechanisms regulating this effect are poorly understood. This study aimed to investigate the pathways underlying the growth inhibition induced by borax in HepG2 cells. The effects of borax on HepG2 cell viability were characterized using MTT. Apoptosis was also verified by annexin V/propidium iodide staining. JC-1 dye and western blotting techniques were used to measure mitochondrial membrane potential and $\mathrm{p} 53, \mathrm{Bax}$, and $\mathrm{Bcl}-2$ protein expression, respectively. Relevant mRNA levels were measured by qRT-PCR. Borax inhibited the proliferation of HepG2 cells in a time- and dosedependent manner in vitro. The apoptotic process triggered by borax involved the upregulation of $\mathrm{p} 53$ and Bax and the downregulation of Bcl-2, which was confirmed by a change in the mitochondrial membrane potential. These results elucidate a borax-induced apoptotic
\end{abstract}


pathway in HepG2 cells that involves the upregulation of p53 and Bax and the downregulation of Bcl-2.

Key words: Borax; HepG2 cells; Apoptosis; p53; Bcl-2; Mitochondrial membrane potential

\section{INTRODUCTION}

Hepatocellular carcinoma (HCC) is the fifth most common cancer worldwide and the third most common reason for cancer-related mortality (Wu et al., 2014). Chemotherapy plays an important role in the treatment of advanced HCC, especially when resection and liver transplantation are inapplicable (Zender et al., 2006; Bruix et al., 2011). However, the most widely used chemotherapeutic drugs today frequently cause side effects. Therefore, the development of effective and safe agents for the prevention and treatment of $\mathrm{HCC}$ is a pertinent area of investigation.

Boron, considered a nutrient element, has been classified as "probably essential" for humans by the World Health Organization (Del Rosso and Plattner, 2014). An increasing number of findings indicate that boron is required for the completion of the life cycle of some higher animals and plays an important role in the replication and development of animal cells. Additionally, a significantly low boron intake impairs bone health, brain function, and the immune response (Nielsen, 2008).

Boron intake has been associated with some cancers. In nature, boron combines to form boric acid and inorganic salts called borates. Borax is a boron compound and a salt of boric acid, which affects the activity of approximately 26 different enzymes in animal, chemical systems, and plant systems (Hunt, 1998).

In recent years, numerous research studies have focused on the use of borax in tumor prevention. Some studies have demonstrated a strong reverse correlation between borax and prostate cancer, lung cancer, cervical cancer, and HCC. A study of 95 cases and 8720 controls showed that low dietary boron intake increases the risk of prostate cancer (Cui et al., 2004). Boric acid inhibits the proliferation of the human prostate cancer cell lines DU145 and LNCaP in vitro in a dose-dependent manner (Barranco and Eckhert, 2004) and also inhibits the growth of LNCaP prostate tumors in nude mice (Gallardo-Williams et al., 2004). Low dietary boron is also associated with the occurrence of cervical cancer and some types of breast cancer (Touillaud et al., 2005; Korkmaz et al., 2007). In the thioacetamide-induced rat model of hepatocellular carcinoma, borax inhibits the proliferating cell nuclear antigen index and attenuates oxidative stress (Zafar and Ali, 2013). These studies demonstrate that borax is a potentially effective anticancer agent and warrants further study.

In this study, we aimed to test the anticancer effect of borax on HepG2 cells, and the underlying molecular mechanisms regulating this effect. Our experimental data showed that borax inhibits the proliferation of HepG2 in a time- and dose-dependent manner. The mechanism of inhibition was investigated by examining the effect of borax on cell apoptosis, mitochondrial membrane potential, and apoptosis-related genes and proteins of the HepG2 cell line.

\section{MATERIAL AND METHODS}

\section{Cell line and reagents}

HepG2, a human hepatoblastoma cell line, was purchased from Professor Guanxin 
Shen, Department of Immunology, Tongji Medical School, Huazhong Science University. HepG2 cells were cultured in RPMI-1640 medium with 10\% fetal bovine serum (Gibco, USA), and maintained in an incubator with a humidified atmosphere of $5 \% \mathrm{CO}_{2}$ at $37^{\circ} \mathrm{C}$. Borax was obtained from Tianjin Bodi Chemical Co. Ltd. (Tianjin, China) and dissolved in sterile deionized water to make a $0.25-\mathrm{M}$ stock solution, with $\mathrm{pH}$ adjusted to 7.3 with boric acid. An annexin V-fluorescein isothiocyanate/propidium (FITC/PI) apoptosis detection kit was obtained from Biosea Biotechnology (Beijing, China). KeyGEN BioTECH (Nanjing, China) was the source of 5, 5',6,6'-tetrachloro-1,1',3,3'-tetraethyl benzimidazole carbocyanine iodide (JC-1). Trypsin and 3-(4,5-dimethylthiazol-2-yl) 2,5-diphenyltetrazolium bromide (MTT) were obtained from Sigma-Aldrich (Germany). Goat anti-p53, rabbit anti-Bcl-2, and anti-Bax antibodies were purchased from Santa Cruz (USA).

\section{MTT assay for cell viability}

Cell viability/proliferation was assessed using the MTT assay. According to the manufacturer instructions, cells were seeded on 96-well plates at a density of $5 \times 10^{3}$ cells/ well and cultured in complete medium for $24 \mathrm{~h}$ before borax exposure. The cells were treated with varying concentrations of borax $(0,0.5,1.0,2.0,4.0,8.0$, and $16.0 \mathrm{mM})$ for 0 , $6,12,24,48$, and $72 \mathrm{~h}$ and cultured in the same medium containing $500 \mu \mathrm{g} / \mathrm{mL}$ MTT for $4 \mathrm{~h}$. Then, the resulting formazan crystals were dissolved in dimethyl sulfoxide $(200 \mu \mathrm{L})$. The absorbance at $490 \mathrm{~nm}\left(\mathrm{~A}_{490 \mathrm{~nm}}\right)$ was measured using an enzyme-labeled meter (Biotek MQX200, USA). The effect of borax treatment on cell viability was evaluated relative to the readings of untreated control cells. The $\mathrm{A}_{490 \mathrm{~nm}}$ represented the number of surviving cells, and the survival rate was calculated as: survival rate $=\left(\mathrm{A}_{\text {treated }} / \mathrm{A}_{\text {control }}\right) \times 100 \%$. Three replications were performed in each group.

\section{Quantification of apoptotic cells by flow cytometry}

The PI and annexin V-FITC double-binding assay was used to identify apoptotic cells using an annexin V-FITC/PI kit. Cells were seeded on 6-well plates, cultured in complete medium for $24 \mathrm{~h}$, and then exposed to borax $(0,1.0,2.0,4.0 \mathrm{mM})$ for $24 \mathrm{~h}$. In accordance with the kit's manual, the cells were harvested, washed twice with PBS, gently resuspended in annexin V binding buffer, and incubated with annexin V-FITC/ PI in the dark for 10 min. Finally, the cells were analyzed by FACS flow cytometry (Becton Dickinson, Franklin Lakes, NJ, USA) with at least $1 \times 10^{6}$ cells per sample. Three replicates were performed in each group.

\section{Measurement of mitochondrial membrane potential (MMP)}

The MMP was observed using the fluorescence microscopy method with JC-1, a lipophilic cationic fluorescent dye. Briefly, 1 x $10^{4} \mathrm{HepG} 2$ cells in a $1000-\mu \mathrm{L}$ volume were distributed on 24-well culture plates and treated with $4.0 \mathrm{mM}$ borax for $0,6,12$, and $24 \mathrm{~h}$. Cells were washed twice with PBS and incubated with JC-1 working solution in an incubator with $5 \% \mathrm{CO}_{2}$ at $37^{\circ} \mathrm{C}$ for $20 \mathrm{~min}$. Next, the stained cells were washed twice with $1 \mathrm{X}$ incubation buffer and observed under an Olympus IX71 fluorescence microscope (Olympus, Shinjuku$\mathrm{ku}$, Tokyo, Japan) at 200X magnification. 


\section{Quantitative RT-PCR (qRT-PCR) analysis}

The expression of apoptosis-related genes was measured by qRT-PCR. The forward primer for 553 was 5'-CCCAGGTCCAGATGAAG-3', and the reverse was 5'-CAGACGGAA ACCGTAGC-3'. The forward primer for Bcl-2 was 5'-GGATGCCTTTGTGGAACTGT-3', and the reverse was 5'-AGCCTGCAGCTTTGTTTCAT-3'. The forward primer for Bax was 5'-TTTGCTTCAGGGTTTCATCC-3', and the reverse was 5'-CAGTTGAAGTTGCCGTCAG A-3'. Total RNA was extracted from the cultured cell lysates with TRIzol Reagent (Invitrogen), and cDNA was synthesized using a RevertAid first-strand cDNA synthesis kit (Fermentas, Canada). The qRT-PCR was performed on a Rotor-gene 6000 System (Corbett Research, Mortlake, New South Wales, Australia) in $20 \mu \mathrm{L}$ qRT-PCR Master Mix (Tiangenin Biotech, Beijing, China). An aliquot of cDNA was added in accordance with the program formulated in pre-tests. The sample was heated to $95^{\circ} \mathrm{C}$ for $5 \mathrm{~min}$ for the first transcription of cDNA, followed by amplification for 35 cycles at $95^{\circ} \mathrm{C}$ for $30 \mathrm{~s}, 60^{\circ} \mathrm{C}$ for $45 \mathrm{~s}$, and $72^{\circ} \mathrm{C}$ for $45 \mathrm{~s}$. Glyceraldehyde3 -phosphate dehydrogenase (GAPDH) was used as the normalization control in qRT-PCR.

\section{Western blot analysis}

To detect changes in apoptosis-related proteins (p53, Bcl-2, and Bax), HepG2 cells (1 $\mathrm{x} 10^{7}$ cells) seeded on a $10-\mathrm{cm}^{2}$ dish were treated with $4.0 \mathrm{mM}$ borax for $0,6,12$, and $24 \mathrm{~h}$. The cells were harvested and lysed using a lysis buffer, and the protein concentrations of the cell lysates were quantified with a protein assay kit. Total protein $(35 \mu \mathrm{g})$ was subjected to $10 \%$ sodium dodecyl sulfate-polyacrylamide gel electrophoresis (SDS-PAGE) for $60 \mathrm{~min}$. Then, the proteins were transferred to a polyvinylidene difluoride membrane and incubated with the following primary antibodies: anti-p53 (1:500), anti-Bcl-2 (1:800), anti-Bax (1:250), and anti$\beta$-actin (1:1000). Next, the membrane was incubated with horseradish peroxidase-conjugated secondary antibody for detection. Finally, the protein-antibody complexes were visualized by chemiluminescence (ECL system, Pierce). The relative fold-difference was calculated by the integration of the OD normalized to the intensity of $\beta$-actin and peroxidase-coupled secondary antibody complexes.

\section{Statistical analysis}

Statistical analysis was performed using SPSS 19.0 for Windows (SPSS, Chicago, IL, USA). The data are reported as means \pm SD. Differences between the borax-treated and control groups were analyzed by one-way analysis of variance (ANOVA). Significance levels were determined by the Student $t$-test. $\mathrm{P}<0.05$ was considered statistically significant.

\section{RESULTS}

\section{Inhibitory effect of borax on HepG2 cell viability}

The effects of borax on the viability of HepG2 cells were tested by the MTT assay. The results revealed that different concentrations of borax could potently inhibit cell growth. Compared to the control group, the number of surviving cells decreased over incubation time and with increasing drug concentrations $(\mathrm{P}<0.05)$ (Figure 1A and B). Even $0.1 \mathrm{mM}$ borax 
could inhibit cell proliferation and promote cell apoptosis after prolonged treatment time (15-20 days; data not shown). This suggests that exposure to low drug concentrations for longer treatment times could result in cytotoxicity comparable to exposure to higher drug concentrations for shorter treatment times. Therefore, this result clearly indicates that the inhibitory effect of borax on HepG2 cell growth was exerted in a time- and concentrationdependent manner.
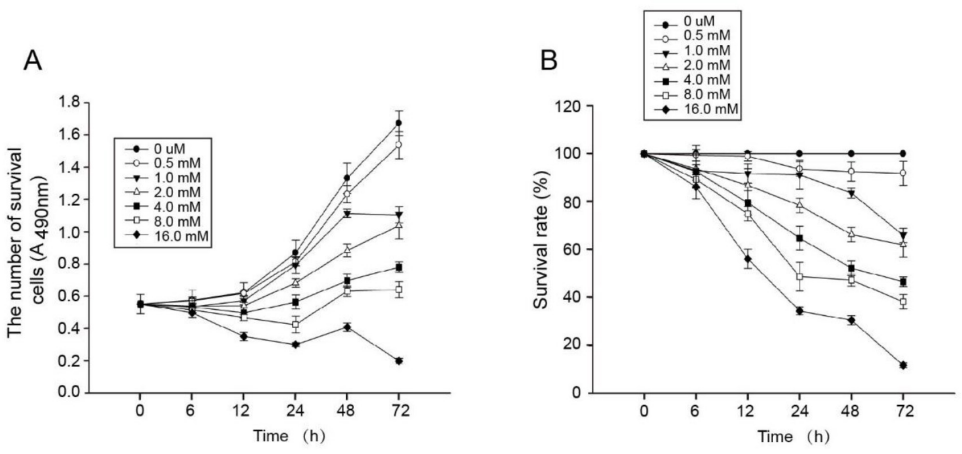

Figure 1. Inhibitory effect of borax on HepG2 cell growth. The effect of borax on the viability of HepG2 cells was assessed using MTT assays. The viability of HepG2 cells is represented by the number of surviving cells in (A) and by the survival rate in (B) as the means $\pm \mathrm{SD}$.

\section{Borax induced apoptosis in HepG2 cells}

HepG2 cells were stained with annexin V-PI and analyzed by flow cytometry to observe apoptosis. The lower-left quadrant in Figure 2 shows intact cells, the lower-right quadrant shows early apoptotic cells, and the upper-right quadrant shows late apoptotic or necrotic cells. Compared with untreated cells, the level of late apoptotic cells increased significantly with different concentrations of borax [from $2.57 \%$ (control) to $8.13,10.4$, and $15.24 \%$ with 0 , $1.0,2.0$, and $4.0 \mathrm{mM}$, respectively; $\mathrm{P}<0.05$ ], and there were significant differences between the groups at $1.0,2.0$, and $4.0 \mathrm{mM}(\mathrm{P}<0.05)$. These results demonstrate that borax induced apoptosis in HepG2 cells in a concentration-dependent manner.
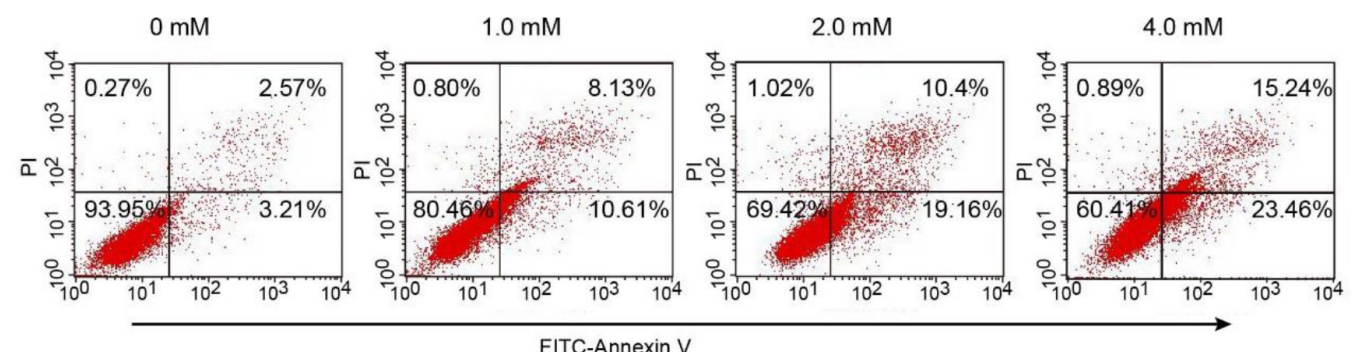

Figure 2. Borax-induced apoptosis in HepG2 cells. HepG2 cells were stained with annexin V-PI and observed using flow cytometry. After incubation with $0,1.0,2.0$, and $4.0 \mathrm{mM}$ borax for $24 \mathrm{~h}$, the percentages of late apoptotic cells were $2.57,8.13,10.4$, and $15.24 \%$, respectively. 


\section{Borax caused depolarization of MMP}

A decrease in MMP is a hallmark of early apoptotic events. Therefore, MMP was measured with JC-1 fluorescent dye to further investigate the effects of borax on mitochondrial function. Cell MMP and early cell apoptosis were detected by a change in JC-1 fluorescence (red to green) using a fluorescence microscope. In the present study, the results showed that borax treatment $(4.0 \mathrm{mM})$ for 6,12 , and $24 \mathrm{~h}$ caused the depolarization of the MMP in HepG2 cells and the degradation of the mitochondria. Compared to the control group, the green fluorescence gradually became significantly stronger $(\mathrm{P}<0.05$; Figure 3$)$, indicating that borax elicited mitochondrial dysfunction in HepG2 cells.

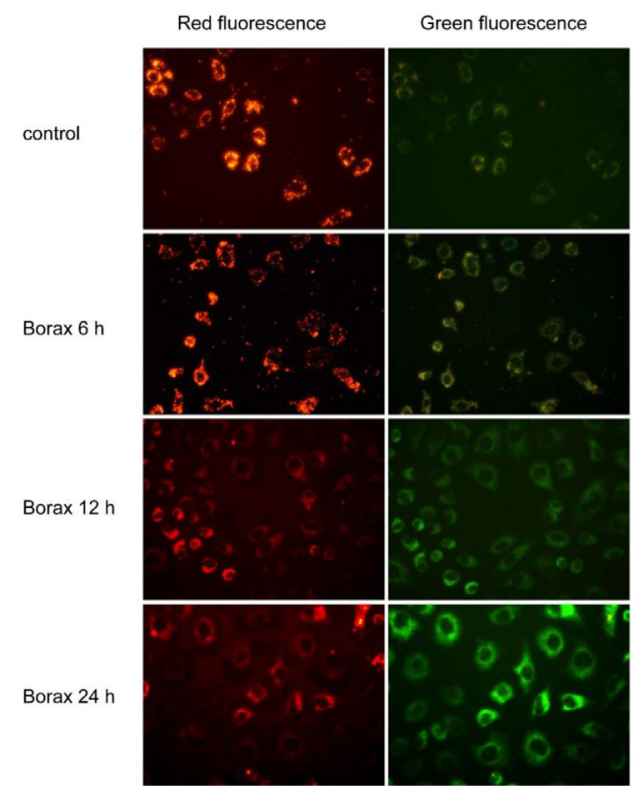

Figure 3. Borax causes the depolarization of the mitochondrial membrane potential. HepG2 cells stained with JC-1 were observed using an Olympus IX71 fluorescence microscope at 200X magnification. Compared to the control group, after exposure to $4.0 \mathrm{mM}$ borax for 6,12 , and $24 \mathrm{~h}$, the green fluorescence gradually became significantly stronger, whereas the red fluorescence gradually attenuated.

\section{Effects of borax on the expression of apoptosis-related genes and proteins in HepG2 cells}

To determine the molecular mechanisms of borax-induced apoptosis in HepG2 cells, the expression levels of several apoptosis-related genes and proteins were examined. The qRTPCR results showed that compared to the untreated group, borax treatment for 6, 12, and 24 $\mathrm{h}$ induced an increase in the mRNA of the tumor suppressor $\mathrm{p} 53$ and pro-apoptotic Bax. It also induced a decrease in the mRNA of the apoptosis regulator $\mathrm{Bcl}-2(\mathrm{P}<0.01)$. There were significant differences among the 6-, 12-, and 24-h treatments $(\mathrm{P}<0.05$; Figure $4 \mathrm{~A})$. The protein expression levels of $\mathrm{p} 53, \mathrm{Bcl}-2$, and Bax were verified by western blotting $(\mathrm{P}<0.05$; Figure 4B). These results illustrate a pathway of apoptosis that involves the modulation of the expression of $\mathrm{p} 53, \mathrm{Bcl}-2$, and Bax in a time-dependent manner. 


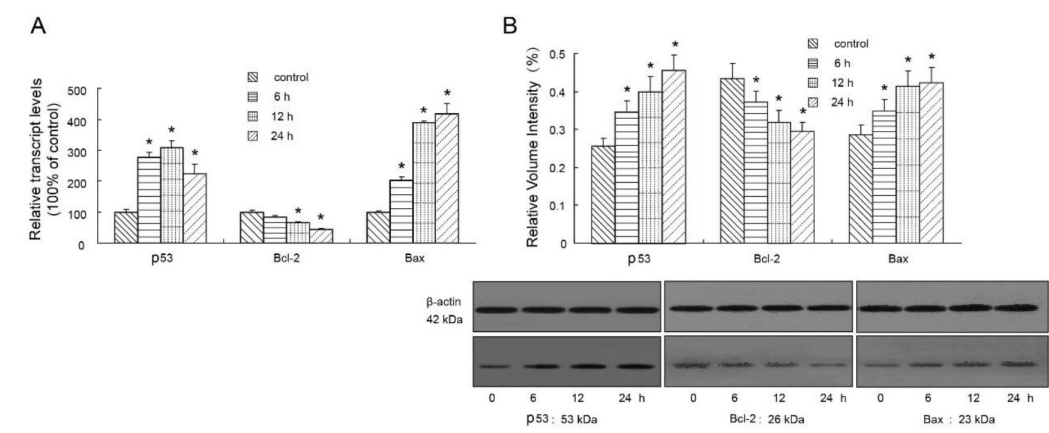

Figure 4. Effects of borax on apoptosis-related genes and proteins. After exposure to $4.0 \mathrm{mM}$ borax for 6,12 , and $24 \mathrm{~h}, \mathrm{mRNA}$ expression of $\mathrm{p} 53$, Bcl-2, and Bax was assessed by quantitative RT-PCR (A), and protein expression of p53, Bcl-2, and Bax was assessed by western blotting in HepG2 cells $(\mathbf{B}) .{ }^{*} \mathrm{P}<0.05$, compared to the control group.

\section{DISCUSSION}

Despite recent advances in anticancer therapies, few effective therapies are available currently. Thus, the development of novel effective drugs with low systemic toxicity is the primary focus of cancer research. Boron is an essential nutrient for normal growth and has recently been shown to be "probably essential" for animals to complete their life cycle, and even humans (Del Rosso and Plattner, 2014). Researchers have noted the primary advantages that boron could provide as opposed to other atoms (iron, etc.) when completing the process of molecular modification during drug synthesis, and boron has been shown to be very helpful in producing agents that can bind and trap important pathophysiological pathways (Nielsen, 2008; Akama et al., 2009, 2013). Borax-based molecules in drug development have been receiving considerable attention recently.

Some studies have shown that borax exerts inhibitory effects on tumor growth (Zafar and Ali, 2013; Seki et al., 2015). The effects of boron-containing chemicals against cancer cells include the inhibition of numerous enzymatic processes and cell division and the induction of apoptosis (Scorei, 2011). However, its effect on HCC cell growth and the mechanisms of inhibition have remained unclear. In the current study, we confirmed that borax reduced the proliferation of the HepG2 cell line in a dose- and time-dependent manner in vitro (Figure 1). These results illustrate the inhibitory effects of borax in HepG2 cells and suggest that borax could serve as a candidate therapeutic agent for HCC.

Apoptosis is a form of programmed cell death and is a crucial pathway for regulating homeostasis, responding to DNA damage, and controlling cell proliferation. Apoptotic cells, including cancerous cells, undergo a natural process of dying (Goldsworthy et al., 1996; Esmaeili et al., 2014). Two major pathways that regulate apoptosis are the cell death receptormediated extrinsic pathway and the mitochondrial-mediated intrinsic apoptotic pathway (Roshan et al., 2014). Cell death also occurs after cytotoxic drug treatment in various cancers, and apoptosis induction is the main strategy of many anticancer drugs (He et al., 2015). To date, the development of anticancer drugs has focused on inititating apoptosis in tumor cells. In addition, substantial evidence shows that apoptosis may change the sensitivity or resistance to anticancer agents (Yuan et al., 2012). In the present study, the inhibition of proliferation and the promotion of apoptosis induced by borax were detected with MTT and annexin V/ PI staining, respectively. The borax-induced inhibition of HepG2 cell growth and apoptosis occurred in a time- and concentration-dependent manner (Figures 1 and 2). 
To delineate the mechanism by which borax inhibits growth and induces apoptosis, we investigated the regulators of these processes. As a tumor-suppressing gene, p53 plays a crucial role in the development of cancer and in responses to stress (p53 elevation signals G1 phase arrest and apoptosis) (Levine, 1997). In particular, the specific inhibition of RNA polI has been shown to kill tumor cells without affecting normal cells in a p53dependent manner (Bywater et al., 2012; Peltonen et al., 2014). Thus, numerous studies will be required to understand the tumor-suppressing activity of the transcription factor p53 and the efficiency of p53-based anticancer therapies (Arlt et al., 2015). Notably, we found in our study that borax induced p53 expression in HepG2 cells, as assessed by western blotting and qRT-PCR (Figure 3), demonstrating that borax might induce apoptosis by upregulating p53.

We also know that $\mathrm{p} 53$ contributes to the transcriptional activation of a large number of target genes, including the pro-apoptotic protein Bax (Mirzayans et al., 2012). Bcl-2 family genes play a key role in controlling the mitochondrial pathway of apoptosis (Dewson and Kluck, 2010; Wu et al., 2013), which consists of pro-apoptosis genes (Bax, Noxa, Puma, Bim, $\mathrm{Bid})$, anti-apoptosis genes (Bcl-2, Bcl-xl), and one of the components of the mitochondrial permeability transition pore (mPTP) (Chen and Lesnefsky, 2011). Thus, as the Bcl-2/Bax protein ratio decreases, the structure and permeability of the MPTP also changes, ultimately leading to a mitochondrial-driven collapse. In the current study, to understand borax-induced apoptosis in HepG2 cells via the mitochondrial pathway, we detected the levels of Bcl-2, Bax, and MMP using western blot, qRT-PCR, and JC-1 fluorescence microscopy, respectively. These results showed that compared to the control group, Bax was significantly upregulated, whereas Bcl-2 was downregulated following exposure to borax for 6,12 , and $24 \mathrm{~h}$. At the same time, the activation of the p53 signaling pathway induced the depolarization of the mitochondrial membrane potential (the gradual change of JC-1 from red fluorescence to green after borax incubation for 6,12, and $24 \mathrm{~h}$ ) (Figures 3 and 4). The change in the structure and permeability of the MPTP is likely due to two main reasons: Firstly, intracellular ROS might increase the expression of Bax while decreasing the expression of $\mathrm{Bcl}-2$, triggering the opening of the mPTP. Additionally, ROS increases the mitochondrial $\mathrm{Ca}^{2+}$ concentration, which in turn favors ATP production and oxidative phosphorylation, promoting the turning on of the mPTP (Zhang et al., 2015). Therefore, we demonstrated the involvement of the mitochondrial apoptosis pathway in the inhibitory effects of borax.

Furthermore, p53 can upregulate Bax in response to a variety of p53-dependent apoptosis triggers. Our results showed that Bcl-2 was downregulated following exposure to borax for 6,12 , and $24 \mathrm{~h}$, whereas Bax was significantly upregulated. Bcl-2 indirectly inhibits apoptosis by inhibiting the opening of permeability transition channels on the mitochondria, whereas Bax promotes apoptosis by an opposing pathway (Rossé et al., 1998). Therefore, the downregulation of Bcl-2 and upregulation of Bax may contribute to borax-induced HCC cell apoptosis.

In conclusion, it is likely that $\mathrm{p} 53$ induction is critically involved in triggering the borax response pathway described in our study, implying that its downstream targets (Bax, Bcl-2) are also important in the mechanisms involved in borax-induced cytotoxicity in HepG2 cells (Figure 5). The p53-mediated apoptosis observed in the present study provides a foundation for understanding the anticarcinogenic effect of borax in HCC and suggests that borax could be a candidate therapeutic drug for HCC. However, further research is needed to verify the underlying molecular mechanisms of borax-induced apoptosis in HCC. 


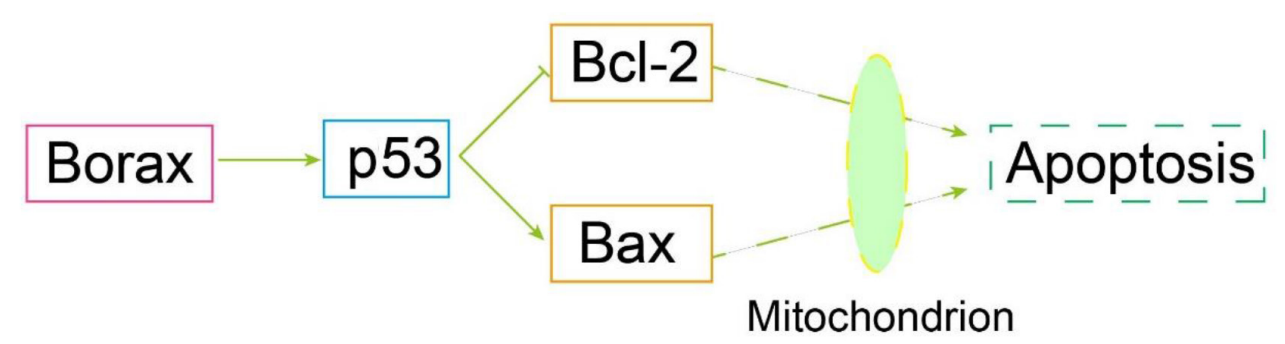

Figure 5. Putative mechanisms responsible for borax-induced apoptosis in HepG2 cells.

\section{Conflicts of interest}

The authors declare no conflict of interest.

\section{ACKNOWLEDGMENTS}

Research supported by the Natural Science Foundation, Hubei Province, China (\#2014CFB310, \#2015CFB615), the Natural Science Foundation of the Hubei Provincial Department of Education (\#B2015468), and the Science and Technology Foundation of Shiyan City (\#15Y56).

\section{REFERENCES}

Akama T, Baker SJ, Zhang YK, Hernandez V, et al. (2009). Discovery and structure-activity study of a novel benzoxaborole anti-inflammatory agent (AN2728) for the potential topical treatment of psoriasis and atopic dermatitis. Bioorg. Med. Chem. Lett. 19: 2129-2132.http://dx.doi.org/10.1016/j.bmcl.2009.03.007

Akama T, Dong C, Virtucio C, Sullivan D, et al. (2013). Linking phenotype to kinase: identification of a novel benzoxaborole hinge-binding motif for kinase inhibition and development of high-potency rho kinase inhibitors. J. Pharmacol. Exp. Ther. 347: 615-625.http://dx.doi.org/10.1124/jpet.113.207662

Arlt C, Ihling CH and Sinz A (2015). Structure of full-length p53 tumor suppressor probed by chemical cross-linking and mass spectrometry. Proteomics 15: 2746-2755; Epub ahead of print http://dx.doi.org/10.1002/pmic.201400549.

Barranco WT and Eckhert CD (2004). Boric acid inhibits human prostate cancer cell proliferation. Cancer Lett. 216: 2129.http://dx.doi.org/10.1016/j.canlet.2004.06.001

Bruix J and Sherman M; American Association for the Study of Liver Diseases (2011). Management of hepatocellular carcinoma: an update. Hepatology 53: 1020-1022. http://dx.doi.org/10.1002/hep.24199

Bywater MJ, Poortinga G, Sanij E, Hein N, et al. (2012). Inhibition of RNA polymerase I as a therapeutic strategy to promote cancer-specific activation of p53. Cancer Cell 22: 51-65.http://dx.doi.org/10.1016/j.ccr.2012.05.019

Chen Q and Lesnefsky EJ (2011). Blockade of electron transport during ischemia preserves bcl-2 and inhibits opening of the mitochondrial permeability transition pore. FEBS Lett. 585: 921-926. http://dx.doi.org/10.1016/j.febslet.2011.02.029

Cui Y, Winton MI, Zhang ZF, Rainey C, et al. (2004). Dietary boron intake and prostate cancer risk. Oncol. Rep. 11: 887-892.

Del Rosso JQ and Plattner JJ (2014). From the test tube to the treatment room: Fundamentals of boron-containing compounds and their relevance to dermatology. J. Clin. Aesthet. Dermatol. 7: 13-21.

Dewson G and Kluck RM (2010). Bcl-2 family-regulated apoptosis in health and disease. Cell Health Cytoskelet. 2: 9-22.

Esmaeili MA, Farimani MM and Kiaei M (2014). Anticancer effect of calycopterin via PI3K/Akt and MAPK signaling pathways, ROS-mediated pathway and mitochondrial dysfunction in hepatoblastoma cancer (HepG2) cells. Mol. Cell. Biochem. 397: 17-31.http://dx.doi.org/10.1007/s11010-014-2166-4

Gallardo-Williams MT, Chapin RE, King PE, Moser GJ, et al. (2004). Boron supplementation inhibits the growth and local expression of IGF-1 in human prostate adenocarcinoma (LNCaP) tumors in nude mice. Toxicol. Pathol. 32: 73-78. http://dx.doi.org/10.1080/01926230490260899

Goldsworthy TL, Conolly RB and Fransson-Steen R (1996). Apoptosis and cancer risk assessment. Mutat. Res. 365: 7190. http://dx.doi.org/10.1016/S0165-1110(96)90013-5 
He W, Liu R, Yang SH and Yuan F (2015). Chemotherapeutic effect of tamoxifen on temozolomide-resistant gliomas. Anticancer Drugs 26: 293-300. http://dx.doi.org/10.1097/CAD.0000000000000197

Hunt CD (1998). Regulation of enzymatic activity: one possible role of dietary boron in higher animals and humans. Biol. Trace Elem. Res. 66: 205-225.http://dx.doi.org/10.1007/BF02783139

Korkmaz M, Uzgören E, Bakirdere S, Aydin F, et al. (2007). Effects of dietary boron on cervical cytopathology and on micronucleus frequency in exfoliated buccal cells. Environ. Toxicol. 22: 17-25.http://dx.doi.org/10.1002/tox.20229

Levine AJ (1997). p53, the cellular gatekeeper for growth and division. Cell 88: 323-331. http://dx.doi.org/10.1016/S0092$\underline{8674(00) 81871-1}$

Mirzayans R, Andrais B, Scott A and Murray D (2012). New insights into p53 signaling and cancer cell response to DNA damage: implications for cancer therapy. J. Biomed. Biotechnol. 2012: 170325.http://dx.doi.org/10.1155/2012/170325

Nielsen FH (2008). Is boron nutritionally relevant? Nutr. Rev. 66: 183-191. http://dx.doi.org/10.1111/j.17534887.2008.00023.x

Peltonen K, Colis L, Liu H, Trivedi R, et al. (2014). A targeting modality for destruction of RNA polymerase I that possesses anticancer activity. Cancer Cell 25: 77-90. http://dx.doi.org/10.1016/j.ccr.2013.12.009

Roshan S, Liu YY, Banafa A, Chen HJ, et al. (2014). Fucoidan induces apoptosis of HepG2 cells by down-regulating p-Stat3. J. Huazhong Univ. Sci. Technolog. Med. Sci. 34: 330-336. http://dx.doi.org/10.1007/s11596-014-1278-0

Rossé T, Olivier R, Monney L, Rager M, et al. (1998). Bcl-2 prolongs cell survival after Bax-induced release of cytochrome c. Nature 391: 496-499. http://dx.doi.org/10.1038/35160

Scorei IR (2011). Calcium fructoborate: plant-based dietary boron as potential medicine for cancer therapy. Front. Biosci. (Schol. Ed.) 3: 205-215.http://dx.doi.org/10.2741/s145

Seki K, Kinashi Y and Takahashi S (2015). Influence of p53 status on the effects of boron neutron capture therapy in glioblastoma. Anticancer Res. 35: 169-174.

Touillaud MS, Pillow PC, Jakovljevic J, Bondy ML, et al. (2005). Effect of dietary intake of phytoestrogens on estrogen receptor status in premenopausal women with breast cancer. Nutr. Cancer 51: 162-169. http://dx.doi.org/10.1207/ $\underline{\mathrm{s} 15327914 \mathrm{nc} 5102 \_}$

Wu L, Fu Z, Zhou S, Gong J, et al. (2014). HIF-1a and HIF-2a: siblings in promoting angiogenesis of residual hepatocellular carcinoma after high-intensity focused ultrasound ablation. PLoS One 9: e88913. http://dx.doi.org/10.1371/journal. pone. 0088913

Wu M, Zhang H, Hu J, Weng Z, et al. (2013). Isoalantolactone inhibits UM-SCC-10A cell growth via cell cycle arrest and apoptosis induction. PLoS One 8: e76000.http://dx.doi.org/10.1371/journal.pone.0076000

Yuan CH, Filippova M and Duerksen-Hughes P (2012). Modulation of apoptotic pathways by human papillomaviruses (HPV): mechanisms and implications for therapy. Viruses 4: 3831-3850. http://dx.doi.org/10.3390/v4123831

Zafar H and Ali S (2013). Boron inhibits the proliferating cell nuclear antigen index, molybdenum containing proteins and ameliorates oxidative stress in hepatocellular carcinoma. Arch. Biochem. Biophys. 529: 66-74. http://dx.doi. org/10.1016/j.abb.2012.11.008

Zender L, Spector MS, Xue W, Flemming P, et al. (2006). Identification and validation of oncogenes in liver cancer using an integrative oncogenomic approach. Cell 125: 1253-1267.http://dx.doi.org/10.1016/j.cell.2006.05.030

Zhang J, Song J, Wu D, Wang J, et al. (2015). Hesperetin induces the apoptosis of hepatocellular carcinoma cells via mitochondrial pathway mediated by the increased intracellular reactive oxygen species, ATP and calcium. Med. Oncol. 32: 101.http://dx.doi.org/10.1007/s12032-015-0516-z 